Advance Journal of Food Science and Technology 5(12): 1543-1547, 2013

DOI:10.19026/rjaset.5.3382

ISSN: 2042-4868; e-ISSN: 2042-4876

(C) 2013 Maxwell Scientific Publication Corp.

Submitted: April 26, $2013 \quad$ Accepted: September 11, $2013 \quad$ Published: December 05, 2013

\title{
Research Article \\ The Dynamic Simulation of Distribution Regularity of Solar Radiation in the Individual Tomato Plant inside the Chinese Solar Greenhouse
}

\author{
Rui Wang, Haihan Wu, Bing Dong, Hui Xu and Tianlai Li \\ College of Horticulture, Shenyang Agricultural University, Shenyang 110866, P.R. China
}

\begin{abstract}
In order to study the radiation regularity of the individual plant inside the Chinese solar greenhouse, the model of plant projection which is based on the geometric structure of tomato is established. In this model, parameters such as, geographic locations, seasons, growing and temporal variations were considered. It has been found that the imitative effect from 10 o'clock to 14 o'clock is better which is based on the error analysis and rootmean-square error detection of different days. Observed values and simulation values in the experimental field from March $28^{\text {th }}$ to April $29^{\text {th }}$ are analyzed by root-Mean-Square Error detection and the RMSE value of azimuth is 1.58 and the RMSE value of plant projected length is 3.38. The model established by this experiment could directly response the distribution regularity of solar radiation in the individual plant inside the Chinese solar greenhouse tomato and the model could provide reference for the solar radiation within the plant population of tomato.
\end{abstract}

Keywords: Distribution regularity, dynamic simulation, greenhouse, tomato

\section{INTRODUCTION}

Solar radiation is one of the most important environmental factors for the yield of tomato inside the Chinese solar greenhouse which is received the energy mainly from the sun (Sun and Chen, 2003; Yang et al., 2009). However, the solar radiation received by plants inside the greenhouse is affected by geographic location of the greenhouse, structure of the greenhouse, planting period, plant growth and plant configuration.

To find out the mechanism of the solar radiation distribution and the effect on some plants inside greenhouse, models were made by some researchers (Sarlikioti et al., 2011; Yuan et al., 2012). A three dimensional reconstruction of maize canopy was established by using ral quadratic equations (Guo and Li, 1999). Considering the direct solar radiation on the maize canopy, a maize canopy model was established. There are also some 3D visual models of canopy on rice by using the visualization of wheatear by L-system (Meng et al., 2005). Models including the photosynthetic rate difference and leaf-age were also established (Li and Geng, 2009).

However, there are few models including parameters (Wu et al., 2009; Shi et al., 2005) such as, geographic location of greenhouse, seasons, growing and temporal variations together with the solar radiation of individual plant. In this study, the relevant parameter of the Sun's orbit visual motion was calculated first and a geometric model of the individual tomato plant was established. To validate the precision of the model, the field measurement was also made. At last, the effect of factors in the model was also discussed.

\section{MATERIALS AND METHODS}

Field planting of tomato is taken in the 29th greenhouse of College of Horticulture of Shenyang Agricultural University on March 20, 2012 using pot cultivation. The variety of the tomato is a cold-sensitive type and the cultivation type is infinite growth. The type of greenhouse is the Chinese solar greenhouse. The geographic coordinate is $123.56^{\circ}$ east longitude and $41.58^{\circ}$ north latitude. The data are measured on March 28 to April 29, 2012. The interval is $1 \mathrm{~h}$ from 8 o'clock to 16 o'clock and 9 sets of data are acquired, every set is measured 3 times for averaging. The length and width of the individual plant of solar greenhouse tomato is measured by tape and white board and the projection azimuth is measured by geologic compass.

\section{Methods:}

- The calculation of relevant parameter of the Sun's orbit visual motion:

- The calculation of declination of sun:

$\delta=0.3723+23.2567 \sin \theta+0.1149 \sin 2 \theta-0.1712 \sin (1)$

$3 \theta-0.758 \cos \theta+0.3656 \cos 2 \theta+0.0201 \cos 3 \theta$

$\theta=2 \pi\left(N-N_{0}\right) / 365.2422$

Corresponding Author: Tianlai Li, College of Horticulture, Shenyang Agricultural University, Shenyang 110866, P.R. China

This work is licensed under a Creative Commons Attribution 4.0 International License (URL: http://creativecommons.org/licenses/by/4.0/). 
$\mathrm{N}$ stands for day which is the order number in a year ( $\mathrm{N}$ equal to 1 when the data is January 1$)$ :

$N_{0}=79.6764+0.2422 \times($ year -1985$)-I N T[($ year -1985$) / 4]$

○ The calculation of solar altitude $(\alpha)$ :

$\sin \alpha=\cos L \cos \delta \cos \tau+\sin L \sin \delta$

L stands for northerly latitudes; $\tau$ stands for true solar hour angle:

$$
\tau=\left(S_{0}-12\right) \times 15^{\circ}
$$

$\mathrm{S}_{0}$ stands for apparent solar time.

Mean solar time which is local time can be figured up by true solar time:

$$
S_{0}=S_{d}+E_{t} / 60
$$

$\mathrm{S}_{\mathrm{d}}$ stands for local time, its unit is hour; Et stands for time difference, its unit is minute:

$$
S_{d}=S+\left\{F-\left[120^{\circ}-(J D+J F / 60)\right] \times 4\right\} / 60
$$

$\mathrm{S}=$ Beijing time, its unit is hour

$\mathrm{F}=$ Beijing time, its unit is minute

$\mathrm{JD}=$ Longitude

$\mathrm{JF}=$ Latitude

The movement of true sun contributes to the variation of time difference and has no relationship with the location. The expression of time difference is:

$$
\begin{aligned}
& \mathrm{Et}=0.0028-1.9857 \sin \theta+9.9059 \sin 2 \theta-7.0924 \\
& \cos \theta-0.6882 \cos 2 \theta
\end{aligned}
$$

○ The calculation of solar azimuth $\left(\mathrm{A}^{\circ}\right)$ :

$$
\cos A_{0}=(\sin \alpha \sin L-\sin \delta) / \cos \alpha \cos L
$$

There is no difference between the three expressions quoted by this experiment and the expressions quoted by ordinary books. Its advantage is that it makes a distinction between the common year and the leap year and eliminates the cumulative effect of calculated value grown progressively due to the leap year. These expressions differentiate different geographic locations and different time. And they have year correction, longitude correction time correction.

- The calculation of projected length (h):

$$
h=M / \tan \alpha
$$

$\mathrm{h}=$ The projected length of individual plant of tomato
$\mathrm{M}=$ The plant height of individual plant of tomato

\section{ANALYSIS METHODS}

- The establishment of plant morphology: The establishment of the model of plant projection is based on the geometric structure of tomato. The type of this experimental material is vigorous growth. The lignified stem height at the base of tomato is 0.5 to $1.5 \mathrm{~m}$. The flower of the vigorous growth is produced terminally at the 7 to $9^{\text {th }}$ lamina of main stem and the main stem is being replaced by the adjacent lateral bud. Then inflorescences inserted on every 2 to 3 laminae. The lateral bud under the inflorescence keeps on growing and forms lamina and inflorescence alternately. The morphology of tomato is fit to the geometrical coin feature. So the cone is chosen to imitate the plant morphology of tomato (Fig. 1).

- The establishment of the plant projection coordinates system:

- The horizontal projection of plant is drawn and all physical quantities are marked

$\alpha$ stands for solar altitude, $\mathrm{A}_{0}$ stands for the projection azimuth of plant, $M$ stands for plant height, $F$ stands for plant width, $\mathrm{c}_{1}$ stands for the vertical distance between the growing tip of the plant and the largest plant width, $\mathrm{c}_{2}$ stands for the vertical distance between the largest plant width and the first leaf, $c_{3}$ stands for

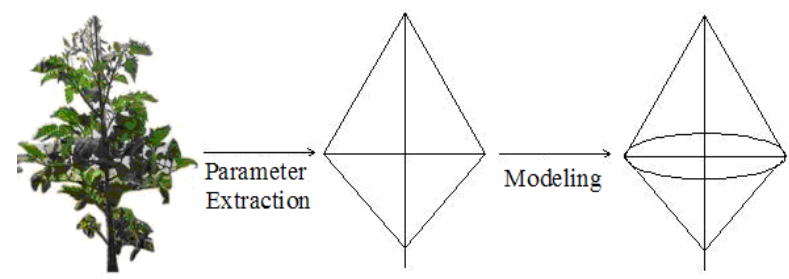

Fig. 1: The establishment of plant morphology of tomato

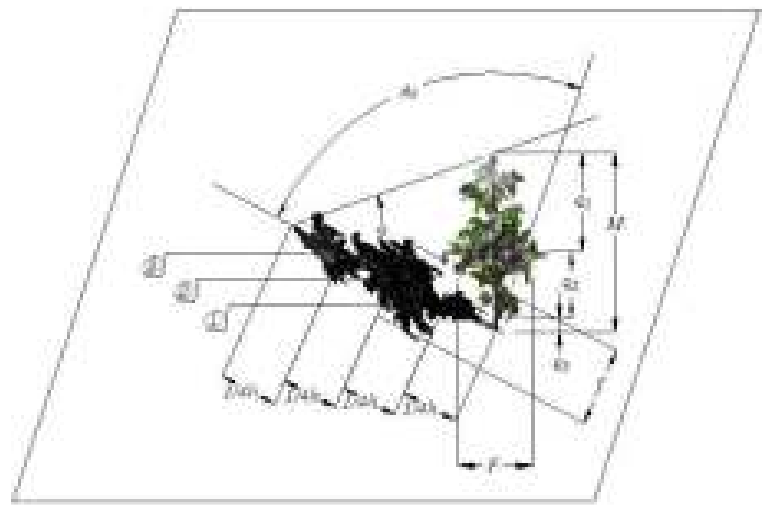

Fig. 2: The diagram of the physical quantities of tomato plant the plant is modeled and rectangular coordinate system is established 


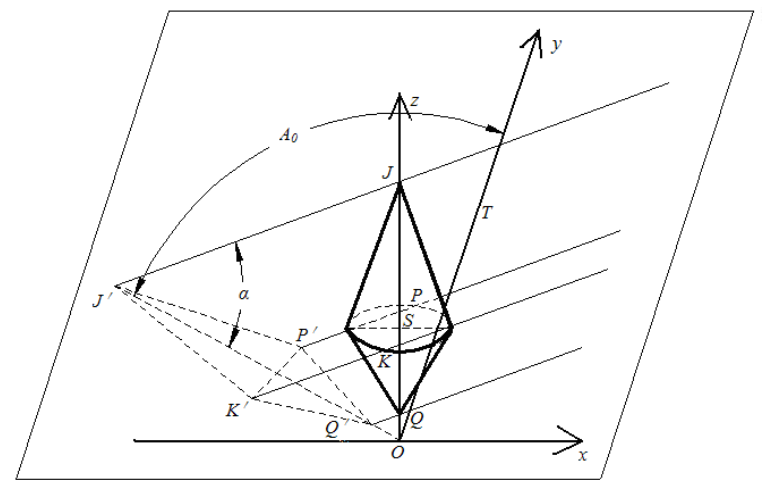

Fig. 3: The establishment of the plant rectangular coordinates system

the vertical distance between the stem base and the first leaf, $h$ stands for the projected length of plant, f stands for projection breadth and (1) (2) (3) points are in the 4 equal-part points (Fig. 2).

The rectangular coordinate is built that due east is going to be along the $\mathrm{x}$-axis, due south is going to be along the y-axis (Fig. 3) and the points of plant is labeled. Point J stands for the highest growing point, point $\mathrm{K}$ and point $\mathrm{P}$ stand for the positions of the maximum plant width. Point $Q$ stands for the position of the first leaf, point $\mathrm{J}^{\prime}$, point $\mathrm{K}^{\prime}$, point $\mathrm{P}^{\prime}$ and point $\mathrm{Q}^{\prime}$ are the projective point of $\mathrm{J}, \mathrm{K}, \mathrm{P}$ and $\mathrm{Q}$. Point $\mathrm{S}$ is located in the axis of plant and point $\mathrm{S}$, point $\mathrm{K}$ and point Pare in one plan. Point $\mathrm{T}$ is on the positive axis of y.

The coordinates of every point coordinate:

$$
\mathrm{JO}=\mathrm{M}, \mathrm{J}^{\prime} \mathrm{O}=\mathrm{m} . \mathrm{KP}=\mathrm{F}, \mathrm{K}^{\prime} \mathrm{P}^{\prime}=\mathrm{f}, \mathrm{JS}=\mathrm{c} 1, \mathrm{SQ}=
$$
$\mathrm{c}_{2}, \mathrm{QO}=\mathrm{c}_{3}, \angle \mathrm{JJ}^{\prime} \mathrm{O}=\alpha, \angle \mathrm{J}^{\prime} \mathrm{OT}=\mathrm{A} 0, \mathrm{~h}=\mathrm{M} \cdot \cot \alpha$

Point J:

$$
x_{\mathrm{J}^{\prime}}=0, \quad y_{J^{\prime}}=0, \quad \mathrm{z}_{J^{\prime}}=M
$$

Point $\mathrm{J}^{\prime}$ :

$$
x_{\mathrm{J}}=-M \cot \alpha \sin A_{0}, \quad y_{\mathrm{J}^{\prime}}=-M \cot \alpha \cos A_{0}, \quad z_{J^{\prime}}=0
$$

Point Q:

$$
x_{Q}=0, y_{Q}=0, \quad z_{Q}=c_{3}
$$

Point Q':

$$
x_{Q^{\prime}}=-\mathrm{c}_{3} \cot \alpha \sin A_{0}, \quad y_{Q^{\prime}}=c_{3} \cot \alpha \cos A_{0}, \quad z_{Q^{\prime}}=0
$$

Point K':

$x_{K^{\prime}}=-\left(c_{2}+c_{3}\right) \cot \alpha \sin A_{0}-\frac{f}{2} \cos A_{0}, \quad y_{K^{\prime}}=\left(c_{2}+c_{3}\right) \cot \alpha \sin A_{0}-\frac{f}{2} \cos A_{0}, \quad z_{K^{\prime}}=0$

Point $\mathrm{P}^{\prime}$ : $x_{p^{\prime}}=-\left(c_{2}+c_{3}\right) \cot \alpha \sin A_{0}+\frac{f}{2} \cos A_{0^{\prime}}, \quad y_{K^{\prime}}=\left(c_{2}+c_{3}\right) \cot \alpha \sin A_{0}+\frac{f}{2} \cos A_{0^{\prime}}, \quad z_{P^{\prime}}=0$

\section{RESULTS AND DISCUSSION}

- The projection rule of plant whose plant height and plant width are the same is simulated in different dates. The projection azimuth and plant projection area are affected by solar altitude and solar azimuth. The simulations of the plants whose plant height is $0.409 \mathrm{~m}$ and plant width is $0.403 \mathrm{~m}$ in March $28^{\text {th }}$, April $13^{\text {th }}$ and April $29^{\text {th }}$ are shown in Fig. 4.

- The projection rules of plant whose plant height are different are simulated in the same date. The projected length, projection breadth and projection azimuth are different as for the different plant heights and plant widths with the same solar altitude and solar azimuth at a given time. The simulations of the plants whose plant heights are $0.409,0.684$ and 0.927 and plant widths are 0.403 , 0.562 and $0.592 \mathrm{~m}$, respectively in March $28^{\text {th }}$ are shown in Fig. 5.

The projected shape and projected area of the individual tomato plant are decided by itself plant morphology and solar altitude. The higher the plant height is and the wider the plant width is, the larger the projected area is. The wider solar altitude is, the closer projection of the growing point is to the base of the plant, the smaller the projected area is and the longer the sun path through plant canopy is. The movement path of plant projection shapes length limited change rules of a butterfly arc belt with the change of solar altitude. And it moved southward from March $28^{\text {th }}$ to April $29^{\text {th }}$.

- The comparison between the actual measurement and the model simulation rule of the plant projection: The actual measurement and the model simulation rule of the plant projection are compared. The imitative effect from 10 o'clock to 14 o'clock is better than that from 8 o'clock to 10 o'clock and 14 o'clock to 16 o'clock based on the error analysis and root-mean-square error detection of different time (Fig. 6).

- The model test of the individual tomato plant: The conformity between the value of simulation and observed value is analyzed by root-meansquare error detection which is the common statistical method when the model is tested. The smaller the RMSE is, the consistency of the value of simulation and measured value is and the more precise the simulated result is. So, the predictability of model simulation value is better mirrored by RMSE, the equation is: 


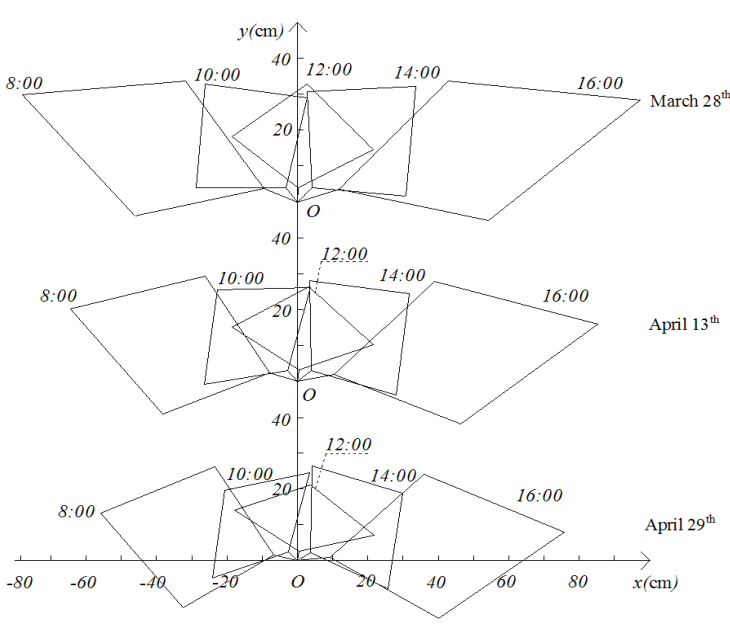

Fig. 4: The simulations of the plants whose plant height is $0.409 \mathrm{~m}$ and plant width is $0.403 \mathrm{~m}$ in different dates

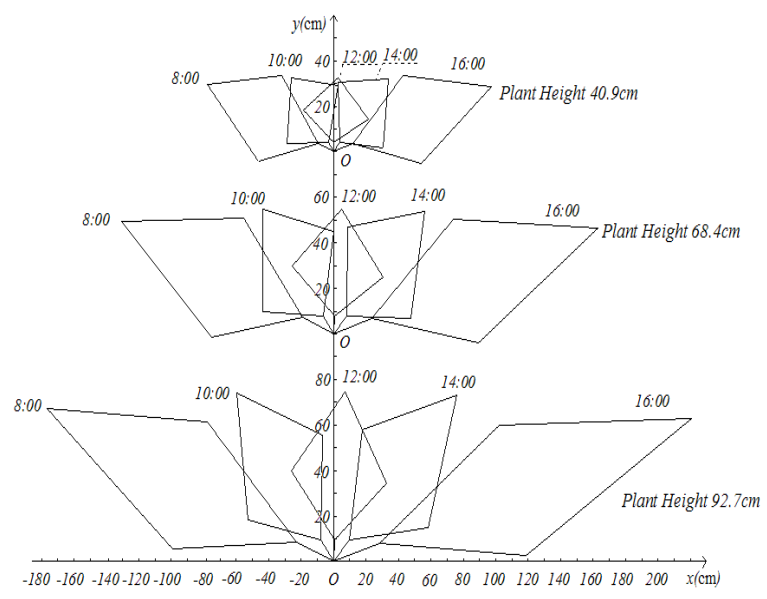

Fig. 5: The simulations of the plants with different plant heights and different plant widths in March 28th

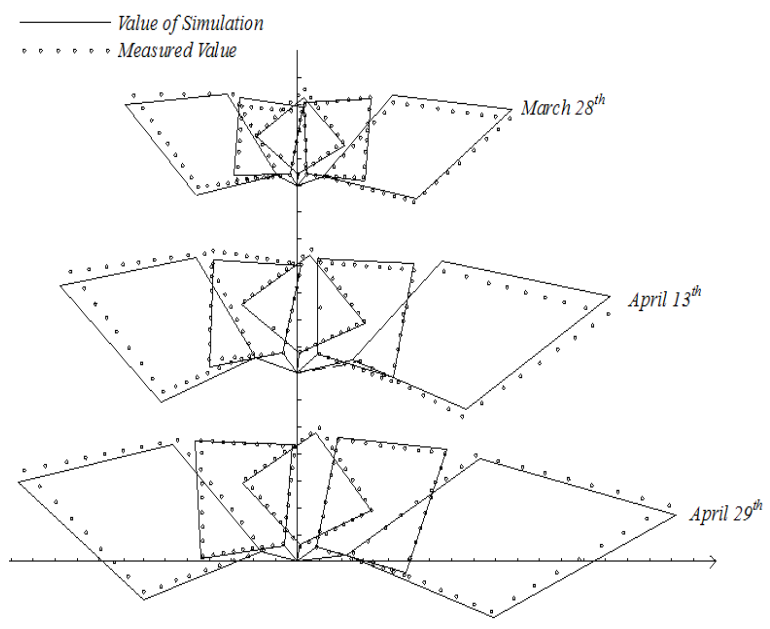

Fig. 6: The comparison between the actual measurement and the model simulation rule of the plant projection in March 2nd, April 13th and April 29th

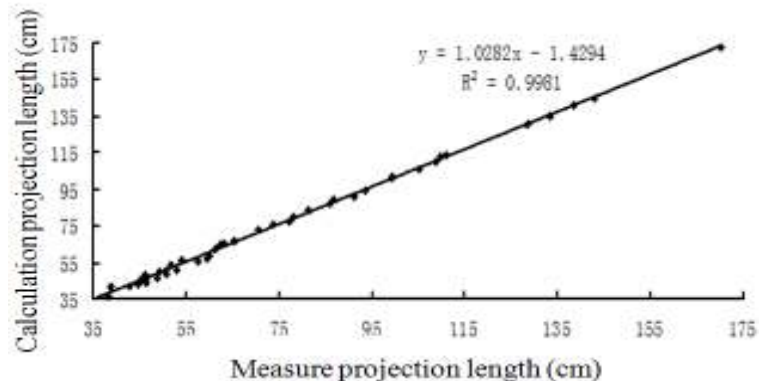

Fig. 7: The linear relation for measured projection length and calculation projection length

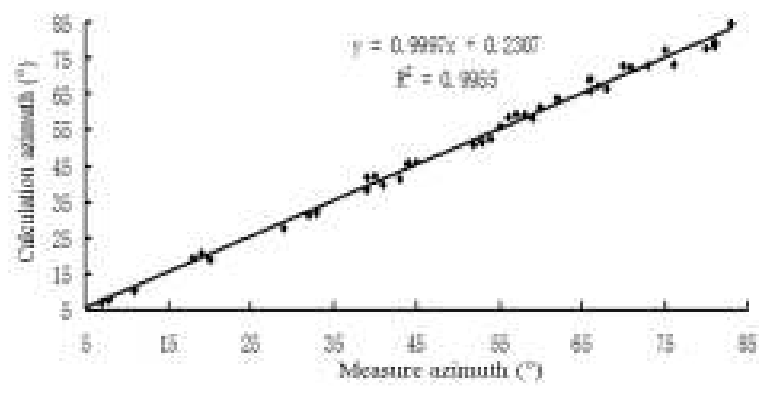

Fig. 8: The linear relation for measured azimuth and calculational azimuth

$$
R M S E=\sqrt{\frac{\sum_{i=1}^{n}\left(O B S_{i}-S I M_{i}\right)^{2}}{n}}
$$

OBSi stands for actual observed value, SIMi stands for model simulation value and $\mathrm{n}$ stands for sample size. The actual observed value and model simulation value of experimental field from March $28^{\text {th }}$ to April $29^{\text {th }}$ are analyzed by root-mean-square error detection and the RMSE value of azimuth is 1.58 and the RMSE value of plant projected length is 3.38 (Fig. 7 and 8).

\section{CONCLUSION}

The individual tomato plant model was established to simulate the distribution regularity of solar radiation and it has achieved this well. The simulation of the plant whose plant height is $0.409 \mathrm{~m}$ and plant width is $0.403 \mathrm{~m}$ in different dates was calculated by this model. The actual observed value and model simulation value of experimental field from March $28^{\text {th }}$ to April $29^{\text {th }}$ are analyzed by Root-Mean-Square Error detection and the RMSE value of azimuth is 1.58 and the RMSE value of plant projected length is 3.38 .

The geometric model of plant morphology can reflect the relation between the plant morphology and solar radiation distribution better than the statistical modelin the individual plant of solar greenhouse tomato. By the dynamic simulation model of solar radiation, the distribution regularity of solar radiation 
under condition of different azimuth angles and different solar altitudes can be accurately calculated easily. Through the analysis of projection simulation, the plant projection azimuth is decided by solar azimuth, the plant projection length is mostly decided by solar altitude. So, the projection area of tomato plant is mainly decided by solar altitude. The dynamic simulation of distribution regularity of solar radiation in the individual plant of solar greenhouse tomato shows that the shape of plant projection is affected by plant morphology and the movement path of plant projection arc a butterfly belt.

\section{ACKNOWLEDGMENT}

The authors thank the National Natural Science Foundation of China (31000921), the Scientific Research Fund of the National Science \& Technology Pillar Program during the $12^{\text {th }} 5$-year Plan Period (2011BAD12B03) for support.

\section{REFERENCES}

Guo, Y. and B. Li, 1999. Mathematical description and three-dimensional reconstruction of maize canopy. Chinese J. Appl. Ecol., 10: 39-41.

Li, M. and N. Geng, 2009. Modeling and visualization of winter wheat spikelet floret organs. J. Agric. Mech. Res., 9: 35-38.
Meng, J., W. Chen and Z. Xu, 2005. Primary study on plant type and computer simulation of 3dimentional structure of rice canopy. Chinese Agric. Sci. Bull., 21: 403-406.

Sarlikioti, V., P.H.B. Visser and L.F.M. Marcelis, 2011. Exploring the spatial distribution of light interception and photosynthesis of canopies by means of a functional-structural plant model. J. Ann. Bot., 107: 875-883.

Shi, W., Q. Chen and X. Qiao, 2005. Preliminary study on the model of the photosynthesis rate of cucumber leaves at different ages and determination of parameters in sunlight greenhouse. T. Chinese Soc. Agric. Eng., 21: 113-118.

Sun, Z. and R. Chen, 2003. A preliminary study on the dynamic model and computer simulation system of greenhouse tomato growth. Chinese J. Eco-Agric., 10:1184-88.

Wu, Y., W. Cao, L. Tang and Y. Zhu, 2009. OpenGLbased visual technology for wheat morphology. T. Chinese Soc. Agric. Eng., 25(1):121-126.

Yang, L., Y. Wangand and M. Kang, 2009. Simulation of tomato growth behavior in response to plantingdensity based on functional-structural model. T. Chinese Soc. Agric. Mach., 40: 156-160.

Yuan, X., W. Wen, X. Guo and C. Wang, 2012. 3Dimentional morphology simulation of tomato canopy-based on measured data. J. Agric. Mech. Res., 2: 171-176. 